\title{
Medazepam Compared with Amylobarbitone in Treatment of Anxiety
}

\author{
R. J. KERRY, C. M. MCDERMOTT
}

British Medical fournal, 1971, 1, 151-152

\section{Summary}

A double-blind crossover comparison of medazepam $10 \mathrm{mg}$ three times a day against amylobarbitone $60 \mathrm{mg}$ three times a day in outpatients with neurotic anxiety showed that medazepam was superior in relieving symptoms. At this dose of medazepam drowsiness or ataxia was rarely a problem.

\section{Introduction}

Medazepam (Nobrium) is a new benzodiazepine, chemically very similar to chlordiazepoxide. It has recently been made available for use in Europe, where it seems to be establishing itself for the treatment of anxiety. Animal studies (Randall, Schallek, Scheckel, Banziger, and Moe 1968) show that it is of low toxicity. Published reports on its clinical use suggest that it is helpful in relieving the symptoms of anxiety (Krakowski, 1967; Daneman, 1969). The evidence about medazepam from controlled trials is, however, limited. The purpose of our present study was to compare the new drug with established therapy. As in our earlier trials we used amylobarbitone as our standard.

\section{Methods}

A preliminary and uncontrolled assessment of medazepam was carried out on inpatients, all of whom were suffering from neurotic anxiety. The dose was varied according to the response obtained, but was generally $10 \mathrm{mg}$ three times a day. Blood and liver function tests were done in all patients.

A double-blind crossover trial was designed to compare medazepam $10 \mathrm{mg}$ three times a day with amylobarbitone $60 \mathrm{mg}$ three times a day for the relief of anxiety in outpatients. The latter dose of amylobarbitone has been previously shown to be suitable for most patients (Jenner and Kerry, 1967). The patients selected were the first 33 new or old cases attending the outpatient department. They were all suffering from neurotic anxiety and were comparable to those patients for whom sedation is commonly and properly prescribed in general practice. There was no selection for either age or sex.

The nature of the trial was explained to the patients, and they were asked to help us in finding which preparation gave them most relief. The trial was arranged on the same lines as our earlier studies (Kerry and Jenner, 1962; Jenner and Kerry, 1967). The patient's condition was assessed at the first visit and changes in his condition were rated during subsequent visits. After a patient's final visit his code was broken and he was maintained on whichever drug had proved to be of most help to him.

Northern General Hospital, Sheffield, S5 7AU

R. J. KERRY, M.R.C.S., D.P.M., Consultant Psychiatrist C. M. MCDERMOTT, M.B., B.A.O., Assistant Psychiatrist

\section{Results}

The dose of medazepam suitable for most patients was $10 \mathrm{mg}$ three times a day, which appeared to relieve the anxiety and was well tolerated. There were no abnormalities in either blood or liver function tests.

Thirty-three patients started the trial and 29 completed the full three weeks on each drug. Of the remainder, two stopped both drugs within a few days of starting them and presumably did not benefit in any way. Another patient was unable to attend hospital for a few weeks after starting the trial because her children had mumps. The other patient who failed to complete had started on amylobarbitone and did not attend again.

The results in terms of the patients' preference for one or other drug are shown in Table I. Most patients preferred medazepam to amylobarbitone $(P<0.01)$. The effectiveness of medazepam for relieving individual symptoms of anxiety when compared with amylobarbitone is also shown. Medazepam was superior for the relief of all the symptoms rated, and this superiority was statistically significant for ruminations $(\mathrm{P}<0.05)$ and phobias $(\mathrm{P}<0.01)$ (Table II). The unwanted effects seen are shown in Table III. Three patients complained of nausea and vomiting on amylobarbitone -unwanted effects of the barbiturates (Sharples, 1965).

TABLE I-Subjective Responses

\begin{tabular}{|c|c|c|c|}
\hline & $\begin{array}{l}\text { No. of } \\
\text { Patients }\end{array}$ & $x^{2 *}$ & Significance \\
\hline 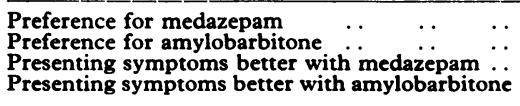 & $\left.\begin{array}{r}24 \\
5 \\
20 \\
5\end{array}\right\}$ & $\begin{array}{l}11 \cdot 18 \\
13 \cdot 78\end{array}$ & $\begin{array}{l}\mathbf{P}<0.01 \\
\mathbf{P}<0.01\end{array}$ \\
\hline
\end{tabular}

*1 Degree of freedom with Yates's correction.

TABLE II-Relief of Symptoms

\begin{tabular}{|c|c|c|c|c|c|c|}
\hline & & \multicolumn{3}{|c|}{ No. of Patients } & \multirow{3}{*}{$x^{2 *}$} & \multirow{3}{*}{ Significance } \\
\hline & & \multirow{2}{*}{$\begin{array}{c}\text { Com- } \\
\text { plaining }\end{array}$} & \multicolumn{2}{|c|}{ Improved with } & & \\
\hline & & & $\begin{array}{l}\text { Meda- } \\
\text { zepam }\end{array}$ & $\begin{array}{c}\text { Amylo- } \\
\text { barbitone }\end{array}$ & & \\
\hline 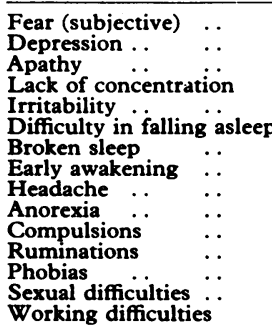 & $\begin{array}{l}\ldots \\
\cdots \\
\cdots \\
\cdots \\
\cdots \\
\cdots \\
\cdots \\
\cdots \\
\cdots \\
\cdots \\
\cdots\end{array}$ & $\begin{array}{r}26 \\
19 \\
12 \\
17 \\
28 \\
17 \\
9 \\
7 \\
17 \\
10 \\
16 \\
16 \\
24 \\
12 \\
16\end{array}$ & $\begin{array}{r}12 \\
7 \\
5 \\
5 \\
9 \\
7 \\
2 \\
2 \\
5 \\
3 \\
6 \\
6 \\
9 \\
1 \\
10\end{array}$ & $\begin{array}{l}5 \\
4 \\
1 \\
2 \\
3 \\
4 \\
2 \\
2 \\
6 \\
2 \\
2 \\
0 \\
0 \\
1\end{array}$ & $\begin{array}{l}3 \cdot 14 \\
0.50 \\
2 \cdot 00 \\
0 \cdot 74 \\
2 \cdot 64 \\
2 \cdot 16 \\
\text { Nil } \\
\text { Nil } \\
\text { Nil } \\
\text { Nil } \\
1.50 \\
5 \cdot 12 \\
8 \cdot 76 \\
\text { Nil } \\
1 \cdot 88\end{array}$ & $\begin{array}{l}\text { N.S. } \\
\text { N.S. } \\
\text { N.S. } \\
\text { N.S. } \\
\text { N.S. } \\
\text { N.S. } \\
\text { N.S. } \\
\text { N.S. } \\
\text { N.S. } \\
\text { N.S. } \\
\text { N.S. } \\
\text { P }<0.05 \\
\text { P }<0.01 \\
\text { N.S. } \\
\text { N.S. }\end{array}$ \\
\hline
\end{tabular}

*1 Degree of freedom with Yates's correction.

TABLE III-Unwanted Effects

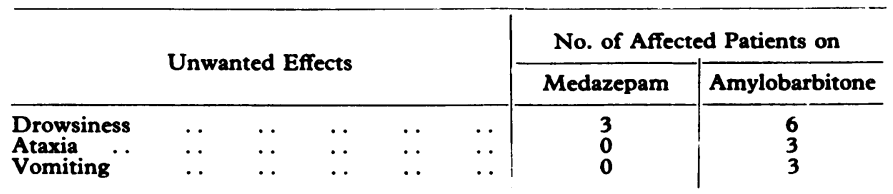




\section{Discussion}

Medazepam, a benzodiazepine, is being used in Europe increasingly for the symptomatic relief of neurotic anxiety, but there have been relatively few carefully controlled trials comparing it with established anti-anxiety drugs. The results of our initial investigation on inpatients confirm that it is effective in relieving anxiety. The optimum dose was $10 \mathrm{mg}$ three times a day, and since there were no abnormalities in liver function or blood tests in this group the drug was considered to be safe for outpatient use.

The results of a double-blind crossover comparison show that medazepam $10 \mathrm{mg}$ three times a day is superior to amylobarbitone $60 \mathrm{mg}$ three times a day for the relief of anxiety in outpatients $(P<0.01)$. This was shown by the patients' responses to one or other of the drugs used in an attempt to relieve their presenting symptoms. This comparison might be criticized on the ground that the dose of amylobarbitone was too low. Higher doses are certainly more effective in relieving anxiety, but at the expense of increased drowsiness. Our own previous experience with amylobarbitone suggests that a $60 \mathrm{mg}$ dose three times a day is probably the best dose for most outpatients. In addition to its overall superiority, medazepam was particularly useful for the relief of ruminations $(P<0.05)$ and phobias $(P<0.01)$. Drowsiness and ataxia were not major problems with medazepam, but we should add that this series contained no elderly patients, who seem to be most vulnerable to those side effects.

A comparison of the results of this trial with a trial of chlordiazepoxide $20 \mathrm{mg}$ three times a day and amylobarbitone $60 \mathrm{mg}$ three times a day (Jenner, Kerry, and Parkin, 1961) suggests that medazepam $10 \mathrm{mg}$ three times a day is at least as therapeutically effective as chlordiazepoxide $20 \mathrm{mg}$ three times a day. In the present study 24 out of 29 patients $(83 \%)$ preferred medazepam, whereas the previous trial showed chlordiazepoxide to be preferred by 59 out of 77 patients $(77 \%)$. A previous comparison of diazepam $5 \mathrm{mg}$ three times a day and amylobarbitone $50 \mathrm{mg}$ three times a day (Jenner and Kerry, 1967) showed that 15 out of 19 patients $(79 \%)$ preferred diazepam for the relief of their anxiety. This suggests that $10 \mathrm{mg}$ of medazepam three times a day also has about the same activity as $5 \mathrm{mg}$ of diazepam three times a day.

To evaluate a new tranquillizer is always difficult, and one would now like to see the results obtained by comparing medazepam with other established tranquillizers. The use of these drugs is often accompanied by initial enthusiasm, to be followed later by disappointment. Psychiatrists are often forced to use the available tranquillizers for the relief of anxiety when perhaps psychotherapy would be more appropriate. This was an outpatient trial and no attempt could be made to keep environmental factors uniform; indeed, it would not have been desirable to do so, since the purpose was to assess the drugs as used in daily practice. It seems that medazepam $10 \mathrm{mg}$ three times a day might offer symptomic relief of anxiety to a considerable proportion of patients without drowsiness and ataxia being a major problem.

We wish to thank Dr. J. E. Orme, chief psychologist, Sheffield Area Psychological Service, for statistical advice and Roche Products Limited for supplying the matching capsules.

\section{References}

Daneman, E. A. (1969). Psychosomatics, 10, 366.

Kerry, R. J., and Jenner, F. A. (1962). Psvchopharmacologia, 3, 302. Jenner, F. A., and Kerry, R. J. (1967). Diseases of the Nervous System, 28, 245.

Jenner, F. A., Kerry, R. J., and Parkin, D. (1961). Fournal of Mental Science, 107,583 .

Krakowski, A. J. (1967). Psvchosomatics, 8, 73.

Randall, L. O., Schallek, W., Scheckel, C., Banziger, R., and Moe, R. A. (1968). Arzneimittel-Forschung, 18, 1542.

Sharples, S. K. (1965). In The Pharmacological Basis of Therapeutics, ed. L. S. Goodman, and A. Gilman, p. 122. New York, Macmillan.

\section{PRELIMINARY COMMUNICATIONS}

\section{New Synthetic Agent for the Induction of Ovulation: Preliminary Trials in Women}

\author{
ARNOLD KLOPPER, MARION HALL
}

British Medical fournal, 1971, 1, 152-154

\section{Summary}

A new compound in the triphenylethylene series has been tested for its effect in causing ovulation in secondary amenorrhoea. Twenty patients were given a total of $\mathbf{4 0}$ courses of treatment and ovulation resulted in 16 instances. Three patients became pregnant. Probably this compound can induce ovulation in suitable subjects.

Department of Obstetrics and Gynaecology, University of Aberdeen, Aberdeen AB9 2ZA

ARNOLD KLOPPER, M.D., F.R.C.o.G., Reader

MARION HALL, M.B., M.R.c.o.G., Lecturer

\section{Introduction}

Clomiphene, a triphenylethylene compound, has been used with modest success for some years to induce ovulation. As marketed, the compound consists of a mixture of cis and trans isomers. The isomer designated by the manufacturers as the cis compound was found to be more potent in stimulating ovulation (Charles et al., 1969). A related compound, $p-\beta$ dimethylaminoethoxyphenyl)-1,2-diphenylbut-1-ene, has recently been synthesized and the cis and trans isomers separated. In contrast to clomiphene it was found that in this case the compound identified as being the trans isomer (Kilbourn et al., 1968) had ovulation-inducing properties. This difference may be more apparent than real, arising from confusion in designation between British and American chemists. The trans isomer, ICI 46,474, had antioestrogenic properties, while the cis isomer behaved like a conventional oestrogen in animal experiments (Harper and Walpole, 1967a). It was of interest to determine whether the trans isomer could also induce ovulation in women, and after extensive toxicological studies permission for a therapeutic trial was obtained from the Committee on the Safety of Drugs.

\section{Patients}

A group of volunteers was sought among patients attending an infertility clinic, selecting those in whom failure of ovula- 